\title{
Impact of Sensory Deprivation on Health Outcome
}

\section{Madhubala Canapathy, Jeystri Kurushev, Felicia Chitra and Manjubala Dash*}

Department of Obstetrics and Gynaecological Nursing, Mother Theresa Post Graduate and Research Institute of Health Sciences, India

*Corresponding Author: Manjubala Dash, Department of Obstetrics and Gynaecological Nursing, Mother Theresa Post Graduate and Research Institute of Health Sciences, India.

Received: September 26, 2019; Published: October 14, 2019

\begin{abstract}
Sensory deprivation otherwise known as perceptual isolation is the purposeful reduction or removal of stimuli from one or more of the senses. Visual, tactile and auditory deprivation are the types of sensory deprivation. Clinically manifested by excessive yawning, hallucination, delusion, depression etc. Sensory deprivation, a condition in which an individual receive less than normal sensory input. Sensory perception dysfunction may have effects on actions of daily living. It can be prevented by encouraging the client to use eyeglass and hearing aids, addressing the client by name and touch the client while speaking, if its not culturally offensive, communicating frequently with the client and maintain meaningful interactions. (e.g., discuss current events). Visual deficits cause problem with self care activities as basic as dressing, toileting, and preparing meals. Auditory, visual hallucination and confusion in time and place indicates that the perceptual disturbances is due to the sensory deprivation symptoms.
\end{abstract}

Keywords: Sensory Deprivation; Health

\section{Introduction}

An individual senses are essential for growth and development and survival. Sensory stimuli give sense to events in the environment. Any alterations in people's sensory function can affect their ability to function within the environment. For example, many clients have damaged sensory function that put them at risk in the health care setting; nurses can help them find ways to function safely in this often confusing environment.

Sensory deprivation otherwise known as perceptual isolation is the intended reduction or removal of stimuli from one or more of the senses. Tools such as blindfolds and earmuffs can cause disturbances in sight and hearing ability while more complex tools can also cut off the sense of smell, touch, taste, thermoception and gravity [1]. Sensory deprivation has been used in various substitute medicines and in psychological experiments.
Types of sensory deprivation

- Visual deprivation: The very fast changes in the ocular dominance of the cells during monocular deprivation.

- Auditory deprivation: It refers to a person's lack of perception of adequate hearing stimulus.

- Tactile deprivation: Deprivation in coma or immobilization.

The long term care of a poorly responsive patient will be confined to bed being turned every 3-4 hours, occasionally being ambulated [1].

Clinical manifestation

- $\quad$ Excessive yawning, drowsiness, sleeping.

- Decreased attention span, difficulty concentration.

- Decreased problem solving.

- Impaired memory.

- $\quad$ Periodic disorientation, general confusion, or nocturnal confusion. 
- $\quad$ Pre occupation with somatic complaints.

- Hallucination or delusion.

- $\quad$ Crying, annoyance over small matters.

- Depression.

- $\quad$ Apathy, emotional lability [2].

Risk factors

- $\quad$ Confined in a non stimulating environment.

- Have impaired vision or hearing.

- Have mobility restriction such as quadriplegia or paraplegia.

- Unable to process stimuli.

- Have emotional disorders.

- $\quad$ Limited social contact with family and friends [2].

Effects of sensory deprivation

Cognitive effect

- $\quad$ Reduced capacity to learn.

- Inability to think.

- Poor task performance.

- Disorientation.

- Regression.

Affective effects

- Boredom.

- Restlessness

- Increased anxiety

- Emotional liability

- Panic.

Perceptual effects

- Color perception

- Apparent movement

- Tactile accuracy

- $\quad$ Time judgment [2-5].

Sensory deprivation in hospital setting

In the hospital such occurrence fall into two general categories,

- $\quad$ Altered sensory reception

- $\quad$ Deprived environment

Altered sensory reception

Occurs in such condition as spinal cord injury, brain damage, change in receptor organs, sleep deprivation, and chronic illness. The person does not receive adequate sensory input because of an interference with the nervous system ability to receive and process stimuli.
Deprived environment

It can have negative effect on a person sensor stasis. A person who is isolated for any reason is deprived of the usual amount of stimulation and may show manifestation of sensory deprivation.

Therapeutic measures for sensory deprivation Communication method

Client with aphasia

- Listen to the client and wait for the client to communicate.

- Use simple short questions, and facial signals to give additional clues.

- If the client has problems speaking, ask such questions, they require simple yes or no answers or blinking of eyes.

- Offer pictures or a communication board so that the clients can point.

- Be calm and patient.

- $\quad$ Give time to understand.

Client with hearing impairment

- Get the client's attention. Do not approach a client from behind.

- $\quad$ Face the client and stand or sit at the same level.

- If the client wears a hearing aid, make sure it is in place and working.

- $\quad$ Speak slowly and clearly.

- Use visible expression, speak with your hand, face and eyes.

- Do not shout.

- Talk towards the client's best or normal ear.

- Use written information to intensify the spoken word.

- Do not restrict a deaf client's hands.

Preventing sensory deprivation

- Encourage the client to use eyeglass and hearing aids.

- Address the client by name and touch the client while speaking, if its not culturally offensive.

- Communicate frequently with the client and maintain meaningful interactions. (eg, discuss current events).

- $\quad$ Provide pictures, sculptures and wall hangings.

- Provide telephone, radio, tv, clock, calendar.

- Having family and friends being freshly cut flowers and plants. 
- Consider having a resident pet such as fish, a cat, or a bird or make arrangements for pet to visit on regular basis.

- Advice to use a sheepskin pillow, silk scarf, soft blanket or other inanimate objects.

- Encourage social interaction through activity groups or visit by family and friends.

- Increase tactile stimulation through physical care measures such as back massage, hair care and foot sock.

- Encourage the use of cross word puzzle or games to stimulate mental function.

- Encourage social interaction through activity group or visit by family and friends.

- Encourage environment changes such as a walk through a mall or for a immobilized patient, sitting near a window.

- Encourage the use of self stimulation technique such as singing, humming, whistling [6-12].

Impact of sensory deprivation on activities of daily living

Sensory perception dysfunction may have effects on actions of daily living. Visual deficits cause problem with self care activities as basic as dressing, toileting, and preparing meals. Hearing deficits may interupt people from watching television, listening to the radio, and answering the telephone. Safety hazards also exist for individual who are having hearing impaired.

People with taste and smell deficits may lose attention in eating. Those with sensory deficit involving touch are at risk for burns and injuries to the extremities. Moving around outside the home may be impossible without the help of special aids.

Many Jobs are prohibited for people with sensory deficit and driving may not be allowed.

This further restricts the environments in which they may move about safety, making them dependent on others. If the affected person is the major earner, a reduction in or loss of income may occur.

People with cognitive dysfunction caused by sensory deprivation or overload may exhibit signs of poor judgment and problem solving during their day to day activities.

\section{Conclusion}

Sensory deprivation, a condition in which an individual receive less than normal sensory input is usually caused by physiological, motor or environmental disruption. Sensory deprivation results in the production of an altered state of consciousness by reducing exteroceptive stimulation and motor activity. Sensory deprivation functions in a similar manner as medication; both reduce the perception of external stimulus. Effects include boredom, inaccurate perception of sensory stimulus. Auditory, visual hallucination and confusion in time and place indicates that the perceptual disturbances is due to the sensory deprivation symptoms.

\section{Bibliography}

1. Kozier Barbara., et al. "Fundamentals of Nursing". VI Edition. India: Pearson Education (2003): 990-997.

2. Ruth F Craven and Constance J Hirnie. "Fundamental of Nursing Human Health And Education". V Edition. New Delhi: Wolters Kluwer, Lippincott Williams And Wilkins (2013): 112-130.

3. June M Thompson., et al. "Manual of Clinical Nursing”. Ii Edition. Missouri: Mosby Company (2008): 706-721.

4. Judith M Wilkinson and Karen Van Lewer. "Fundamentals of Nursing, Theory Concept and Application". I Edition. Philodelphis: Jaypee Publication (2008): 691-700.

5. Potter and Perry. Fundamentals of Nursing. III Edition. Missouri: Mosby Publication (2003): 1552-1571.

6. Clement I. Textbook of Nursing Foundation. II Edition. Bengaluru: Jaypee Publication (2017): 708-710.

7. Taylor R Carol., et al. The Art and Science of Nursing Care. VI Edition. New Delhi: Wolter Kluwer, Lippincott Williams And Wilkins (2016): 1021-1030.

8. Lewis, Bucher. "Medical- Surgical Nursing- Assessment and Management of Clinical Problems". Elsevier Publication, 7th Edition (2008): 1603.

9. Suzzane and Brenda. "Medical Surgical Nursing". Lippincott Publication, 10th Edition.

10. Sigma. Global Nursing Excellence. Jane Pearson Shelby June. Journal of Nursing Scholarship (1978).

11. Philip Soloman., et al. The American Journal of Psychiatry 114.4 (2011): 357-365

12. Nursing Research. Official Journal of Eastern Nursing Research and Society. The Western Institute of Nursing 20 (1971): 46-54.

\section{Volume 2 Issue 11 November 2019} (C) All rights are reserved by Manjubala Dash., et al. 